\title{
Conformers, electronic states, and diabolical conical intersections in the valence photoelectron spectroscopy of halocyclohexanes
}

\author{
Cite as: J. Chem. Phys. 153, 054305 (2020); doi: 10.1063/5.0018293 \\ Submitted: 16 June 2020 - Accepted: 15 July 2020 • \\ Published Online: 3 August 2020
}

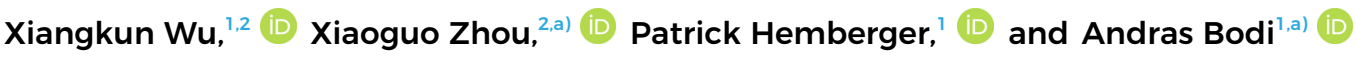

\section{AFFILIATIONS}

${ }^{1}$ Laboratory for Synchrotron Radiation and Femtochemistry, Paul Scherrer Institute, 5232 Villigen, Switzerland

${ }^{2}$ Hefei National Laboratory for Physical Sciences at the Microscale, Department of Chemical Physics, University of Science and Technology of China, Hefei 230026, China
\end{abstract}

a) Authors to whom correspondence should be addressed: xzhou@ustc.edu.ch and andras.boedi@psi.ch

\begin{abstract}
The threshold photoelectron spectrum (TPES) of halocyclohexanes $\mathrm{C}_{6} \mathrm{H}_{11} \mathrm{X}(\mathrm{X}=\mathrm{Cl}, \mathrm{Br}$, and $\mathrm{I})$ was recorded at the Swiss Light Source and assigned with the help of density functional theory and equation-of-motion ionization potential coupled cluster calculations. Dyson orbitals show that the first two electronic states of the cation arise by symmetry breaking of the doubly degenerate $e_{\mathrm{g}}$ orbitals in cyclohexane as perturbed by the halogen or by perturbation of the halogen lone pair by the cyclohexane ring scaffold in the case of light and heavy halogen substituents, respectively. When the resulting two states $\left(\mathrm{A}^{\prime \prime}\right.$ and $\left.\mathrm{A}^{\prime}\right)$ are coupled via a conical intersection in $C_{S}$ symmetry, they are smoothly connected by molecular orbital rotation when the nuclear symmetry is relaxed. Even then, barriers at avoided crossings lead to distinct $\mathrm{A}^{\prime}$ and pseudo- $\mathrm{A}^{\prime \prime}$ minima, which contribute to the TPES separately. As axial and equatorial conformers are present in commensurate abundance at room temperature, four transitions are conceivable for each substituent in the low-energy range. Three of these could be identified, and their energy could be determined for each sample. Transitions to $\mathrm{A}^{\prime}$ states are associated with a smaller geometry change and exhibit stronger origin transitions. Yet, most notably in $\mathrm{X}=\mathrm{Br}$, they do not correspond to the adiabatic ionization energy, which is indicated by a weak and broad band to the pseudo- $\mathrm{A}^{\prime \prime}$ state with a lower onset energy. Franck-Condon vibrational analysis of the TPES coupled with quantum chemical calculations can provide insights into the behavior of conformers as well as strongly coupled electronic states.
\end{abstract}

Published under license by AIP Publishing. https://doi.org/10.1063/5.0018293

\section{INTRODUCTION}

Molecular structure and isomerism have profound influence on chemical reactivity. Perhaps surprisingly, photolysis products of the 1-iodopropane ion, the propanal ion, ${ }^{2}$ and thiophenols, as well as the fragments in the dissociative photoionization of alanine, ${ }^{4}$ are isomer-/conformer-dependent. At ambient conditions, conformers usually interconvert quickly, which often blurs out conformer-specific reactivity. However, for instance, in catalytic semihydrogenation, which is a promising technique to yield alkenes from alkynes, ${ }^{5}$ the key to diastereomeric selectivity may lie with the isomeric distribution of the reactive intermediates. This shows why, besides of fundamental interest, understanding conformational isomerism is also important in the context of applied research.
Constitutional isomers often have significantly different ionization energies, which allows for their isomer-selective detection by photoionization mass spectrometry. ${ }^{6,7}$ Diastereomers routinely exhibit at most slightly different spectral signatures, which make their identification challenging without very high resolution techniques, such as ZEKE. ${ }^{8}$ Substituted cyclohexanes are a textbook example of conformational isomerism as they exhibit intriguing conformational behavior. ${ }^{9}$ Monosubstituted cyclohexanes have two distinctly different stable diastereomers: the equatorial (e-) and the axial (a-) chair structure, depending on whether the substituent is in the ring plane or perpendicular to it, respectively.

Photoelectron photoion coincidence (PEPICO) spectroscopy, combined with tunable vacuum ultraviolet (VUV) synchrotron 
radiation, ${ }^{10-12}$ can afford a detailed snapshot of photoionization to investigate dissociative ionization mechanisms and energetics, ${ }^{13,14}$ thanks to its multiplexing advantages. ${ }^{15}$ By virtue of the coincident photoion time-of-flight (TOF) analysis, photoion mass selected photoelectron spectra can be plotted and combined with the FranckCondon (FC) vibrational structure analysis. This approach has proven to be a powerful, isomer-selective analytical tool in the analysis of reactive mixtures. ${ }^{16,17}$ It has revealed the role of the electronic state in fragmentation processes of small halogen-substituted molecular ions, ${ }^{18,19}$ unveiled complex dissociation mechanisms with parallel and sequential steps, ${ }^{20,21}$ and delivered accurate thermochemistry and energetics of elusive species. ${ }^{22-24}$ Furthermore, the two diastereomers, trans and cis, of the 1-methylallyl radical in pyrolysis ${ }^{25}$ and combustion $^{26}$ environments could also be identified, similar to the fingerprints of the axial and equatorial conformers of fluorocyclohexane, $\mathrm{C}_{6} \mathrm{H}_{11} \mathrm{~F}$, with only a few tens of $\mathrm{meV}$ ionization energy difference. ${ }^{2}$

In $\mathrm{C}_{6} \mathrm{H}_{11} \mathrm{~F}^{27}$ the equatorial and axial conformers were distinguished based on the room-temperature threshold photoelectron spectrum (TPES) and Franck-Condon modeling. Geometry optimization of the $\mathrm{C}_{6} \mathrm{H}_{11} \mathrm{~F}^{+}$cation showed that the axial structure has two, almost isoenergetic minima with $C_{1}\left(\tilde{\mathbf{X}}^{+2} \mathrm{~A}\right)$ and $C_{\mathrm{S}}\left(\tilde{\mathbf{A}}^{+}{ }^{2} \mathrm{~A}^{\prime}\right)$ symmetries, while only a $C_{1}$ minimum could be located for the equatorial conformer near the ionization onset. The first excited state of the equatorial cation, of $C_{\mathrm{S}}\left(\tilde{\mathbf{A}}^{+2} \mathrm{~A}^{\prime}\right)$ symmetry, lies $\sim 0.6 \mathrm{eV}$ higher in energy, although the conformers themselves are also almost isoenergetic in the ground state. If ionization is thought of as removing an electron from a molecular orbital, such differences between conformer ionization energies indicate that-all similarities of the neutral conformational isomers aside- profound electronic structure differences may lurk beneath the surface, which can lead to different chemical behaviors of the neutrals, as well.

Photoelectron spectroscopy combined with Franck-Condon simulations can be used to characterize cation ground and excited states. ${ }^{28}$ In previous experiments on monohalogenated silacyclohexanes, ${ }^{29}$ trends could be established in the electronic and bonding structure as a function of the halogen size. This motivated us to study the photoelectron spectra of heavier halocyclohexanes $\left(\mathrm{C}_{6} \mathrm{H}_{11} \mathrm{X}, \mathrm{X}\right.$ $=\mathrm{Cl}, \mathrm{Br}$, and I) to gain insights into their electronic structure and conformational behavior as a function of the halogen.

Neutral $\mathrm{C}_{6} \mathrm{H}_{11} \mathrm{X}(\mathrm{X}=\mathrm{Cl}, \mathrm{Br}$, and I) has previously been studied by, e.g., electron diffraction; ${ }^{30,31}$ nuclear magnetic resonance (NMR); ${ }^{32,33}$ and microwave, ${ }^{34-37}$ Raman, ${ }^{38,39}$ and IR spectroscopies. ${ }^{40-44}$ The conformational equilibrium was also investigated computationally. ${ }^{45,46}$ These studies focused mainly on the conformational energy and have shown that the population of axial conformer is $23 \%-45 \%$ for $\mathrm{C}_{6} \mathrm{H}_{11} \mathrm{Cl}, 18 \%-30 \%$ for $\mathrm{C}_{6} \mathrm{H}_{11} \mathrm{Br}$, and $\approx 26 \%$ for $\mathrm{C}_{6} \mathrm{H}_{11} \mathrm{I}$ at ambient temperature, meaning that the axial and equatorial conformers are nearly isoenergetic. As reported in the literature $^{32}$ and confirmed by our preliminary calculations, the interconversion rate between the two conformers is on the order of $10^{5} \mathrm{~s}^{-1}$ at room temperature, meaning that thermal equilibrium is reached within a few $\mu$ s.

A handful of experiments have addressed the ionic states of $\mathrm{C}_{6} \mathrm{H}_{11} \mathrm{X}^{+}$. Sergeev et al. ${ }^{47}$ recorded the photoelectron spectrum of $\mathrm{C}_{6} \mathrm{H}_{11} \mathrm{Cl}$ and $\mathrm{C}_{6} \mathrm{H}_{11} \mathrm{Br}$ at $16.8 \mathrm{eV}$ photon energy and reported vertical ionization energies for the ground and excited electronic states. Tian et al. used HeI photoelectron spectroscopy and Penning ionization to study the ionization of $\mathrm{C}_{6} \mathrm{H}_{11} \mathrm{Cl}$ and $\mathrm{C}_{6} \mathrm{H}_{11} \mathrm{Br}$. They assigned the bands, reported ionization energies, and discussed spin-orbit coupling (SOC) based on the $300 \mathrm{meV}$ splitting observed for $\mathrm{C}_{6} \mathrm{H}_{11} \mathrm{Br}^{48,49}$ Due to limited spectral modeling possibilities and insufficient resolution, the conformer-specific features were not addressed in these works. The ionization energies for the equatorial and axial bromocyclohexane conformers could first be determined selectively by high resolution vacuum ultraviolet mass-analyzed threshold ionization (VUV-MATI) as $9.8308 \mathrm{eV}$ and $9.8409 \mathrm{eV}$, respectively. ${ }^{50}$ However, the authors only considered one cation structure for each conformer to assign the spectra. As we have seen in $\mathrm{C}_{6} \mathrm{H}_{11} \mathrm{~F},{ }^{27}$ the differences between the experimental spectrum and the Franck-Condon simulation may indicate that there are multiple close-lying cationic electronic states near the ionization threshold in one or both conformers. A high-resolution TPES and FranckCondon simulations may help us address this issue also for $\mathrm{C}_{6} \mathrm{H}_{11} \mathrm{X}^{+}$ $(\mathrm{X}=\mathrm{Cl}, \mathrm{Br}$, and $\mathrm{I})$.

\section{EXPERIMENTAL AND COMPUTATIONAL}

Experiments were carried out at the VUV beamline of the Swiss Light Source, Paul Scherrer Institute, using the double imaging Photoelectron Photoion Coincidence (CRF-PEPICO) spectrometer. The details of the beamline and the CRF-PEPICO spectrometer were described elsewhere, ${ }^{51,52}$ and only a brief description is included here. Synchrotron radiation was produced in a bending magnet, collimated, dispersed by a grazing incidence monochromator with a 600 lines/mm laminar grating, and focused at the exit slit in a differentially pumped gas filter at a photon energy resolution of $2 \mathrm{meV}$ at $8 \mathrm{eV}$. To suppress higher-order radiation above $15.7 \mathrm{eV}$, a differentially pumped gas filter was filled with a mixture of argon and neon at a pressure of 10 mbar over an optical length of $10 \mathrm{~cm}$. The photon energy was calibrated using the autoionization lines of argon in the first and second diffraction orders of the grating.

The halogenated cyclohexane samples $\left(\mathrm{C}_{6} \mathrm{H}_{11} \mathrm{X}, \mathrm{X}=\mathrm{Cl}, \mathrm{Br}, \mathrm{I}\right)$ were purchased from Sigma-Aldrich, Inc. and used without further purification. The sample vapors were introduced from the headspace of a vial through a needle valve via 6-mm Teflon tubing directly into the ionization region of the experiment at room temperature, where they were intersected with the VUV beam. The photoelectrons and ions were extracted in opposite directions by a constant, $125 \mathrm{~V} \mathrm{~cm}^{-1}$, electric field. Velocity map imaging and space focusing conditions were maintained to collect electrons and ions, respectively, as detected by position-sensitive delay-line anode detectors (Roentdek, DLD40) at the respective end of the flight tubes. Threshold electrons with less than $2 \mathrm{meV}$ kinetic energy are imaged at the center of the detector, together with energetic electrons without an off-axis momentum component. The ensuing hot electron contamination of the threshold signal was subtracted as proposed by Sztáray and Baer. ${ }^{53}$ As the electron TOF is negligible relative to the ion TOF, the electron signal is used as the start signal to record the TOF of the coincident cation. ${ }^{54}$ Plotting the coincident threshold electron signal with a cation in the TOF-range of an $\mathrm{m} / \mathrm{z}$ of interest as a function of photon energy yields the photoion mass-selected threshold photoelectron spectrum (ms-TPES). At the ionization onset, in the energy range in which the parent ion is stable, its ms-TPES 
agrees with the TPES. At higher photon energies, the sum of the parent and fragment ion ms-TPES yields the TPES, as plotted later herein.

Photoelectron spectra were simulated by calculating FranckCondon factors, i.e., the nuclear wave function overlaps between the neutral molecule and the corresponding cation assuming a harmonic potential for both and including Duschinsky rotations to account for changes in the normal modes upon ionization, ${ }^{55}$ on the basis of geometry optimizations and frequency analyses using density functional theory (DFT). The DFT level of theory was chosen so that it reproduced the potential energy surface features determined by equation-of-motion ionization potential coupled cluster calculations (EOM-IP-CCSD, see below). Namely, the B3LYP/6$311++\mathrm{G}(\mathrm{d}, \mathrm{p})$ level was used for $\mathrm{X}=\mathrm{Cl}$ and $\omega \mathrm{B} 97 \mathrm{X}-\mathrm{D} / \mathrm{def} 2-\mathrm{TZVPP}$ for $\mathrm{X}=\mathrm{Br}$ and $\mathrm{I}$. Ionization energies could then be accurately obtained by shifting the simulated spectrum so that it reproduced the vibrational fine structure of the first TPES band. These calculations were performed using the Gaussian 16 A.03 program package. ${ }^{56}$ In addition, we also applied EOM-IP-CCSD to optimize the geometries, calculate ionization energies, unveil the behavior of the first two electronic states, and plot Dyson orbitals using the Q-Chem 4.3 program package. ${ }^{57}$ Dyson orbitals represent the overlap between an initial $N$-electron wave function of the neutral and the $N-1$-electron wave function of the cation, ${ }^{58}$ i.e., the molecular orbital of the leaving electron, which frequently agrees with the Hartree-Fock highest occupied molecular orbital (HOMO) for the ground electronic cation state, but often has contributions from multiple molecular orbitals for electronically excited cation states. Geometry optimizations were carried out using the 6-311G(d) basis set, and ionization energies were calculated using the ccpVTZ basis set, in conjunction with the Stuttgart/Cologne effective core potential ${ }^{59}$ for $\mathrm{X}=\mathrm{Br}$ and I (cc-pVTZ-PP). Unrelaxed potential energy curves were also obtained connecting the cation stationary points on the potential energy surface by interpolation in a redundant internal coordinate system ${ }^{60}$ in both $C_{\mathrm{S}}$ and $C_{1}$ symmetries.

Inevitably, the magnitude of the error due to approximations in our computational approach will change as a function of halogen size. The triple- $\zeta$ basis sets used in both geometry optimizations and energy calculations are not large enough to deliver chemical accuracy. Yet, they allow us to have a balanced description of the wave function across the series and are unlikely to be the biggest source of error in the case of $\mathrm{Br}$ or I. Relativistic corrections including spin-orbit splitting and the Born-Oppenheimer approximation are justifiably neglected in fluorine, but may be quite significant in iodine. ${ }^{61}$ While some relativistic effects are addressed by the effective core potential used for $\mathrm{Br}$ and $\mathrm{I}$, we neglect the spin-orbit coupling (SOC) in the calculations. As a matter of fact, as the character of the electron hole in the cations becomes dominated by the halogen lone pair as the halogen size increases (see below), the spin-orbit splitting could be expected to converge to that observed in isolated halogen atoms, i.e., $0.05 \mathrm{eV}, 0.11 \mathrm{eV}, 0.46 \mathrm{eV}$, and $0.94 \mathrm{eV}$ for $\mathrm{F}, \mathrm{Cl}, \mathrm{Br}$, and I, respectively. ${ }^{62}$ In the spectra analyzed herein, this only affects the Franck-Condon fit to the $\mathrm{X}=\mathrm{Cl}$ sample, in which the SOC may be commensurate with the features of the vibrational fine structure at the ionization onset. In $\mathrm{X}=\mathrm{Br}$ and I, SOC is addressed experimentally as the spin-orbit split states show up as separate bands in the TPES.

\section{RESULTS AND DISCUSSIONS}

\section{A. Threshold photoelectron spectra}

Figures $1(\mathrm{~b})-1(\mathrm{~d})$ show the measured TPES of $\mathrm{C}_{6} \mathrm{H}_{11} \mathrm{Cl}$, $\mathrm{C}_{6} \mathrm{H}_{11} \mathrm{Br}$, and $\mathrm{C}_{6} \mathrm{H}_{11} \mathrm{I}$. For comparison, we also plot the TPES of $\mathrm{C}_{6} \mathrm{H}_{11} \mathrm{~F}$ in Fig. 1(a) recorded under analogous experimental conditions. ${ }^{27}$ For $\mathrm{C}_{6} \mathrm{H}_{11} \mathrm{~F}$ and $\mathrm{C}_{6} \mathrm{H}_{11} \mathrm{Cl}$, very similar spectral contours are observed in Figs. 1(a) and 1(b) with distinct vibrational fine structure at the ionization onset followed by several, mostly structureless bands. Moreover, the maximum of the first TPE band is located at $\sim 0.5 \mathrm{eV}$ higher than the onset, which is indicative of a moderate molecular geometry change upon ionization. The TPES of $\mathrm{C}_{6} \mathrm{H}_{11} \mathrm{Br}$ and $\mathrm{C}_{6} \mathrm{H}_{11} \mathrm{I}$ in Figs. 1 (c) and 1(d) looks different, especially in the region close to the ionization onset. Two much narrower bands can be clearly observed with distinct vibrational structure. The first peak in the vibrational progression has the maximal intensity, which is indicative of a small geometry change and close to vertical origin transition in ionization in $\mathrm{X}=\mathrm{Br}$ and $\mathrm{I}$.

In addition, the second TPE band has the same contour as the first one for $\mathrm{X}=\mathrm{Br}$ and $\mathrm{I}$ and rises in an energy range without vertical transitions according to the EOM-IP-CCSD calculations. This means that they can be readily assigned to the spin-orbit splitting of the cation ground electronic state. For $\mathrm{C}_{6} \mathrm{H}_{11} \mathrm{Br}$, the energy gap of $0.30 \mathrm{eV}$ agrees exactly with the literature value, ${ }^{49}$ as well as with the SOC upon ionization of methyl bromide of $0.32 \mathrm{eV},{ }^{63}$ and is about two thirds of the $0.46 \mathrm{eV}$ splitting in the isolated bromine atom. The $0.49 \mathrm{eV}$ splitting in the $\mathrm{C}_{6} \mathrm{H}_{11} \mathrm{I}$ TPES is, however, only half the iodine splitting of $0.94 \mathrm{eV}$ and also significantly smaller than the SOC of $0.62 \mathrm{eV}$ observed in the iodomethane cation. ${ }^{64}$ Extrapolating the magnitude of SOC to chlorine and fluorine is, therefore, quite difficult. In the photoelectron spectrum of chloromethane and fluoromethane, SOC is not readily identified and is also commensurate with the Jahn-Teller coupling. ${ }^{65}$ All in all, SOC could account for a splitting of max. $30 \mathrm{meV}$ for $\mathrm{X}=\mathrm{Cl}$, which makes the assignment of the corresponding TPES [see Fig. 1(b) below] less certain, while it is only expected to contribute slightly to peak broadening in the TPES of $\mathrm{X}=\mathrm{F}$.

After the vibrationally resolved rising edge in the TPES, there is an almost constant TPE signal up to $14 \mathrm{eV}$ photon energy. EOMIP-CCSD calculations were used to predict the vertical transitions at the neutral geometries, which indicate the maximum of the corresponding TPES band. The slight drops in intensity at around $13 \mathrm{eV}$ $\left(\mathrm{C}_{6} \mathrm{H}_{11} \mathrm{~F}\right.$ and $\left.\mathrm{C}_{6} \mathrm{H}_{11} \mathrm{Cl}\right)$ and $14 \mathrm{eV}\left(\mathrm{C}_{6} \mathrm{H}_{11} \mathrm{Br}\right.$ and $\left.\mathrm{C}_{6} \mathrm{H}_{11} \mathrm{I}\right)$ are quite well reproduced by the absence of vertical transitions in this energy range. Broadly speaking, the ionization energies and the geometry change upon ionization decrease with an increase in the halogen atomic number as ionization occurs from the cyclohexane ring molecular orbitals in the case of $\mathrm{X}=\mathrm{F}$ and shifts progressively to the halogen lone pair in $\mathrm{X}=\mathrm{Br}$ and $\mathrm{I}$ (see below).

\section{B. Franck-Condon spectral simulations}

We observed a distinct vibrational fine structure at the onset of each TPE spectrum in Fig. 1. In fluorocyclohexane, we previously found that transitions into an equatorial and two nearly isoenergetic axial cation states were responsible for the vibrational fine structure, and the spectra could only be reproduced by including all three contributions in the Franck-Condon simulation. ${ }^{27}$ Based on 

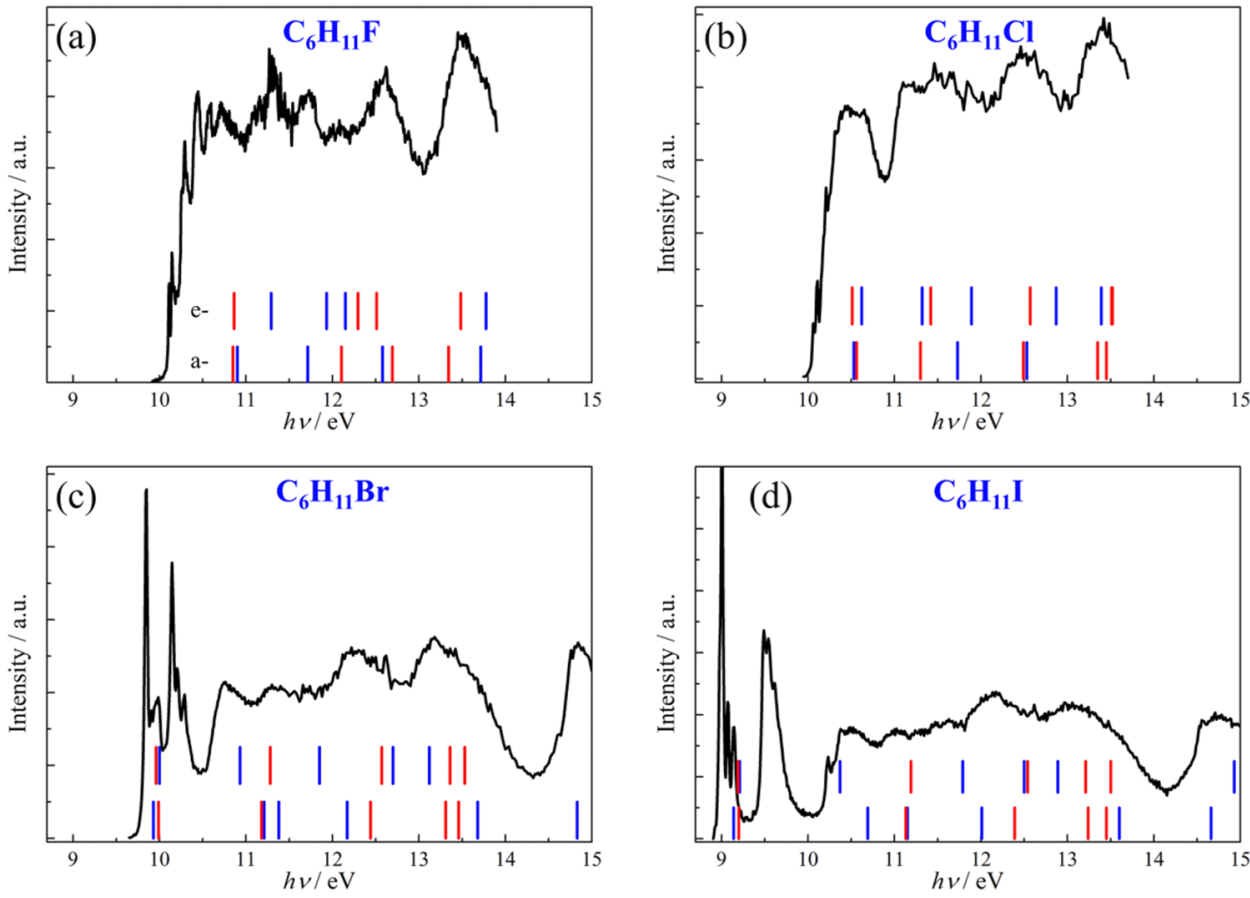

FIG. 1. Threshold photoelectron spectra of fluorocyclohexane (a), chlorocyclohexane (b), bromocyclohexane (c), and iodocyclohexane (d). The sticks show the vertical ionization energies calculated at the EOM-IP-CCSD/cc-pVTZ level for the e-conformer (upper level) and a-conformer (lower level). Red and blue sticks indicate $A^{\prime \prime}$ and $A^{\prime}$ states, respectively. the insights delivered by EOM-IP-CCSD calculations (see below), we have generalized our approach to model the low-energy part of TPES of the heavier halogen analogs reported in this paper. As we will show later, a low barrier separates the two minima, the $\tilde{\mathbf{X}}^{+}$pseudo- $\mathrm{A}^{\prime \prime}$ and $\tilde{\mathbf{A}}^{+} \mathrm{A}^{\prime}$ states in the axial fluorocyclohexane cation. The vibrational degree(s) of freedom coupling to the internal conversion will be anharmonic as a result, which is not taken into account in our harmonic Franck-Condon factor calculations. Both direct and indirect ionization mechanisms may yield threshold electrons, ${ }^{66}$ which may distort relative peak intensities if, e.g., autoionization cross sections vary. ${ }^{67}$ Furthermore, low-lying conical intersections may result in exceedingly short excited-state lifetimes and, thus, natural peak broadening. Accounting for these effects and spin-orbit coupling quantitatively lies beyond the capabilities of standard quantum chemical approaches for mid-sized molecules. Yet, we successfully modeled all three TPES by including all transitions to cation states our non-relativistic harmonic DFT calculations deemed important. By doing so over four spectra consistently, we believe that the simulations and our approach are arguably validated.

Similar to $\mathrm{C}_{6} \mathrm{H}_{11} \mathrm{~F}^{27}$ three cationic minima play a role at the ionization onset of $\mathrm{C}_{6} \mathrm{H}_{11} \mathrm{Cl}$, which are computed to be (1) a$\mathrm{C}_{6} \mathrm{H}_{11} \mathrm{Cl}\left(C_{\mathrm{S}}, \mathrm{A}^{\prime}\right) \rightarrow \mathrm{a}-\mathrm{C}_{6} \mathrm{H}_{11} \mathrm{Cl}^{+}\left(C_{1}, \tilde{\mathbf{X}}^{+}\right.$pseudo- $\left.\mathrm{A}^{\prime \prime}\right)$ at $10.16 \mathrm{eV},(2)$ $\mathrm{a}-\mathrm{C}_{6} \mathrm{H}_{11} \mathrm{Cl}\left(C_{\mathrm{S}}, \mathrm{A}^{\prime}\right) \rightarrow \mathrm{a}-\mathrm{C}_{6} \mathrm{H}_{11} \mathrm{Cl}^{+}\left(C_{\mathrm{S}}, \tilde{\mathbf{A}}^{+} \mathrm{A}^{\prime}\right)$ at $10.27 \mathrm{eV}$, and (3) e- $\mathrm{C}_{6} \mathrm{H}_{11} \mathrm{Cl}\left(C_{\mathrm{S}}, \mathrm{A}^{\prime}\right) \rightarrow \mathrm{e}-\mathrm{C}_{6} \mathrm{H}_{11} \mathrm{Cl}^{+}\left(C_{1}, \tilde{\mathbf{X}}^{+}\right.$pseudo- $\left.\mathrm{A}^{\prime \prime}\right)$ at $10.12 \mathrm{eV}$ (see Table I). The transition to the equatorial $\tilde{\mathbf{A}}^{+} \mathrm{A}^{\prime}$ cationic state of

TABLE I. Vertical and adiabatic ionization energies to the $A^{\prime}$ and $A^{\prime \prime}$ states in $C_{S}$ and adiabatic ionization energy to the pseudo- $A^{\prime \prime}$ minimum for axial and equatorial $C_{6} H_{11} X(X$ $=\mathrm{F}, \mathrm{Cl}, \mathrm{Br}$, and I), calculated at the EOM-IP-CCSD/cc-pVTZ(-PP)//EOM-IP-CCSD/6-311G(d) level of theory and extracted from the FC simulation of the TPES. The positions of two transitions for $\mathrm{X}=\mathrm{Br}$ have been established accurately by VUV-MATI as $9.8308 \mathrm{eV}$ (indicated by "a") and $9.8409 \mathrm{eV}$ (indicated by "b"). 50

\begin{tabular}{|c|c|c|c|c|c|c|c|c|c|c|c|c|c|}
\hline \multirow[b]{2}{*}{$\mathrm{IE} / \mathrm{eV}$} & & \multicolumn{3}{|c|}{$\mathrm{C}_{6} \mathrm{H}_{11} \mathrm{~F}$} & \multicolumn{3}{|c|}{$\mathrm{C}_{6} \mathrm{H}_{11} \mathrm{Cl}$} & \multicolumn{3}{|c|}{$\mathrm{C}_{6} \mathrm{H}_{11} \mathrm{Br}$} & \multicolumn{3}{|c|}{$\mathrm{C}_{6} \mathrm{H}_{11} \mathrm{I}$} \\
\hline & & Vertical & Adiabatic & Exp. & Vertical & Adiabatic & Exp. & Vertical & Adiabatic & Exp. & Vertical & Adiabatic & Exp. \\
\hline \multirow{3}{*}{ a- } & $\mathrm{A}^{\prime}$ & 10.90 & 10.33 & 10.15 & 10.52 & 10.27 & 10.11 & 9.95 & 9.87 & $9.84^{\mathrm{a}}$ & 9.19 & 9.12 & 8.98 \\
\hline & $A^{\prime \prime}$ & 10.85 & 10.26 & & 10.54 & 10.24 & & 10.01 & 9.93 & & 9.25 & 9.19 & \\
\hline & \multicolumn{2}{|c|}{ Pseudo-A"A } & 10.19 & 10.12 & & 10.16 & 10.06 & & & & & & \\
\hline \multirow{3}{*}{ e- } & $\mathrm{A}^{\prime}$ & 11.29 & 10.83 & & 10.62 & 10.52 & & 10.03 & 9.95 & $9.85^{\mathrm{b}}$ & 9.26 & 9.21 & 9.01 \\
\hline & $A^{\prime \prime}$ & 10.86 & 10.25 & & 10.49 & 10.21 & & 9.97 & 9.89 & & 9.24 & 9.18 & \\
\hline & \multicolumn{2}{|c|}{ Pseudo-A" } & 10.21 & 10.15 & & 10.12 & 10.06 & & 9.81 & 9.71 & & 9.17 & 8.99 \\
\hline
\end{tabular}




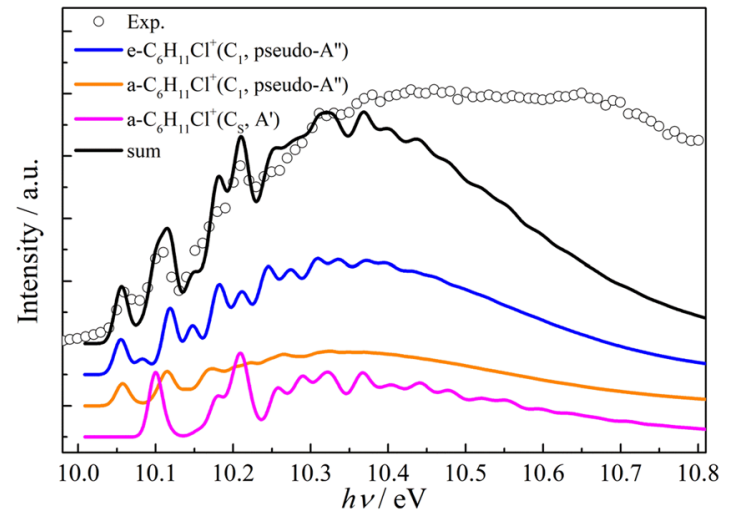

FIG. 2. Experimental and simulated TPE spectra of $\mathrm{C}_{6} \mathrm{H}_{11} \mathrm{Cl}$ near the ionization onset. The FC model including three ionizing transitions is detailed in the text.

$C_{S}$ symmetry is computed to lie at $10.52 \mathrm{eV}$ and does not contribute close to the ionization onset. Thus, one equatorial and two axial conformer minima are produced in the ionic ground-state band and contribute to the TPES in Fig. 1(b). The Franck-Condon simulated line spectrum was convoluted with a Gaussian distribution with a full width at half maximum (FWHM) of $160 \mathrm{~cm}^{-1}(0.02 \mathrm{eV})$ to account for the rotational envelope at the sample temperature of $298 \mathrm{~K}$ (Fig. 2). The overall simulated spectrum is the sum of the three components, and only the ionization thresholds are shifted slightly to fit to the experimental result. Based on recent experimental results, the axial and equatorial conformer populations of $\mathrm{C}_{6} \mathrm{H}_{11} \mathrm{Cl}$ are $34 \%$ and $66 \%$. ${ }^{43}$ The weights of the three traces are determined as their thermal population ratios at room temperature. However, we have found that the fit is quite insensitive to the assumed population ratios. This is due to the contour of the equatorial and axial pseudo- $\mathrm{A}^{\prime \prime}$ state spectra being rather similar. Thus, the relative conformational abundances are constrained by the sharper $\mathrm{A}^{\prime}$ progression of the axial conformer. The Franck-Condon simulation relies on the sudden approximation, i.e., on the absence of intermediate states. Furthermore, we assume constant photoelectron dipole matrix elements, i.e., the transition probability is independent of the final cation electronic state. The involvement of intermediate neutral (mostly Rydberg) states in the ionization exacerbates the errors due to the sudden approximation and cancels some due to the second one. Finally, also because of the unresolved effect of spin-orbit coupling, a conclusive assignment of the spectral features would require a highly resolved pulsed-field ionization experiment to identify rovibrational transition conformer and electronic state selectively.

In the simulation in Fig. 2, the two transitions of e- $\mathrm{C}_{6} \mathrm{H}_{11} \mathrm{Cl}$ $\left(C_{\mathrm{S}}, \mathrm{A}^{\prime}\right) \rightarrow \mathrm{e}-\mathrm{C}_{6} \mathrm{H}_{11} \mathrm{Cl}^{+}\left(C_{1}, \tilde{\mathbf{X}}^{+}\right.$pseudo- $\left.\mathrm{A}^{\prime \prime}\right)$ and a- $\mathrm{C}_{6} \mathrm{H}_{11} \mathrm{Cl}\left(C_{\mathrm{S}}, \mathrm{A}^{\prime}\right)$ $\rightarrow \mathrm{a}-\mathrm{C}_{6} \mathrm{H}_{11} \mathrm{Cl}^{+}\left(C_{1}, \tilde{\mathbf{X}}^{+}\right.$pseudo- $\left.\mathrm{A}^{\prime \prime}\right)$ have almost identical band origins at $10.05 \pm 0.01 \mathrm{eV}$, while the other transition of a- $\mathrm{C}_{6} \mathrm{H}_{11} \mathrm{Cl}\left(\mathrm{C}_{S}\right.$, $\left.\mathrm{A}^{\prime}\right) \rightarrow \mathrm{a}-\mathrm{C}_{6} \mathrm{H}_{11} \mathrm{Cl}^{+}\left(C_{\mathrm{S}}, \tilde{\mathrm{A}}^{+} \mathrm{A}^{\prime}\right)$ starts from a slightly higher energy of $10.10 \mathrm{eV}$. Taking into account the Stark shift of $8 \mathrm{meV}$ at the constant $125 \mathrm{~V} \mathrm{~cm}^{-1}$ extraction field, ${ }^{66}$ the adiabatic ionization energies to these final states are $10.06 \pm 0.01 \mathrm{eV}, 10.06 \pm 0.01 \mathrm{eV}$, and $10.11 \pm$ $0.02 \mathrm{eV}$, respectively.

Compared with $\mathrm{C}_{6} \mathrm{H}_{11} \mathrm{X}(\mathrm{X}=\mathrm{F}$ and $\mathrm{Cl})$, the Dyson orbitals of the first two cationic states of $\mathrm{C}_{6} \mathrm{H}_{11} \mathrm{X}(\mathrm{X}=\mathrm{Br}$ and $\mathrm{I})$ exhibit a more pronounced non-bonding halogen lone-pair character (see below). This diminishes the geometry change upon ionization and leads to a more pronounced vibrational structure near the ionization threshold, as seen in Fig. 1. Similar to $\mathrm{X}=\mathrm{F}$ and $\mathrm{Cl}$, three ionization transitions were considered for $\mathrm{C}_{6} \mathrm{H}_{11} \mathrm{Br}$ and $\mathrm{C}_{6} \mathrm{H}_{11} \mathrm{I}$, but only one for the axial and two for the equatorial conformer: a- $\mathrm{C}_{6} \mathrm{H}_{11} \mathrm{X}\left(C_{\mathrm{S}}\right.$, $\left.\mathrm{A}^{\prime}\right) \rightarrow \mathrm{a}-\mathrm{C}_{6} \mathrm{H}_{11} \mathrm{X}^{+}\left(C_{S}, \tilde{\mathbf{X}}^{+} \mathrm{A}^{\prime}\right), \mathrm{e}-\mathrm{C}_{6} \mathrm{H}_{11} \mathrm{X}\left(C_{S}, \mathrm{~A}^{\prime}\right) \rightarrow \mathrm{e}-\mathrm{C}_{6} \mathrm{H}_{11} \mathrm{X}^{+}\left(C_{1}\right.$, $\tilde{\mathbf{X}}^{+}$pseudo- $\left.\mathrm{A}^{\prime \prime}\right)$, and e- $\mathrm{C}_{6} \mathrm{H}_{11} \mathrm{X}\left(C_{S}, \mathrm{~A}^{\prime}\right) \rightarrow \mathrm{e}-\mathrm{C}_{6} \mathrm{H}_{11} \mathrm{X}^{+}\left(C_{S}, \tilde{\mathbf{A}}^{+} \mathrm{A}^{\prime}\right)$. There are significant differences between the contributing electronic states when compared with $\mathrm{X}=\mathrm{F}$ and $\mathrm{Cl}$. As will be shown later, the stability of the $A^{\prime}$ state increases with the halogen size, and it becomes more stable than the pseudo- $\mathrm{A}^{\prime \prime}$ state in the axial bromine conformer. It is also associated with a less geometry change, which is why the origin transition and the vibrational progression belonging to the axial and equatorial $\mathrm{A}^{\prime}$ states dominate the spectrum. On the other hand, the pseudo- $\mathrm{A}^{\prime \prime}$ state is still considerably more stable in the bromine equatorial conformer, which is why it contributes to a broadband with an onset markedly below the $\mathrm{A}^{\prime}$ origin transitions. The calculated line spectra were convoluted with $160 \mathrm{~cm}^{-1}$ FWHM Gaussian (Fig. 3) to account for rotational broadening as in $\mathrm{X}=\mathrm{Cl}$.

In addition to the strong, albeit rather broad vibrational peak near the threshold in the $\mathrm{X}=\mathrm{Br}$ and I TPES, a shoulder is distinctly visible at the lower energy side of the main peak of $\mathrm{C}_{6} \mathrm{H}_{11} \mathrm{I}$. This
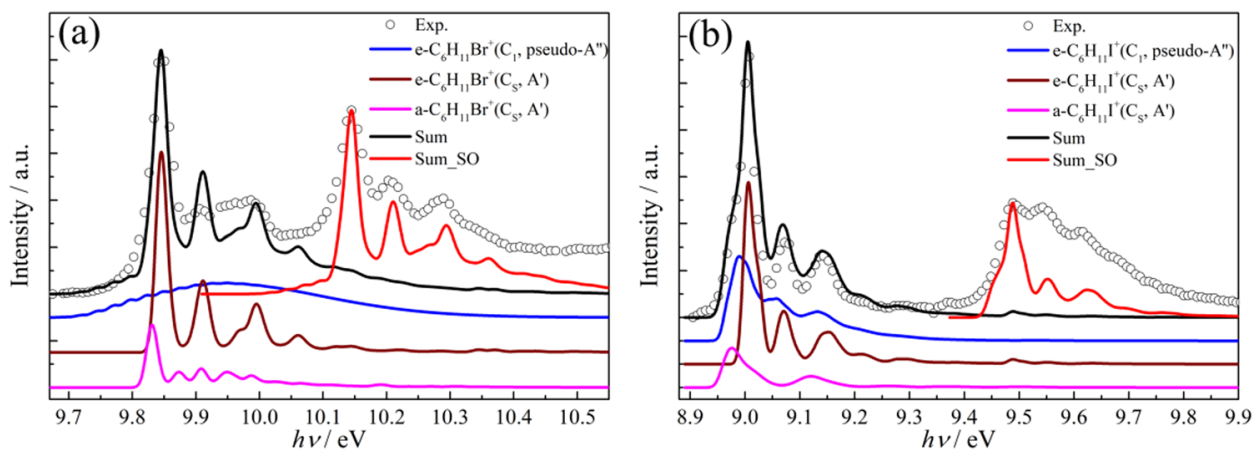

FIG. 3. Experimental and simulated TPE spectra of (a) $\mathrm{C}_{6} \mathrm{H}_{11} \mathrm{Br}$ and (b) $\mathrm{C}_{6} \mathrm{H}_{11} \mathrm{I}$ near threshold photoionization, obtained as a sum of the respective contributions of the equatorial and axial conformers (see text). 
wide spectral contour cannot be due to hot or sequence bands or rotational broadening at room temperature, and transitions from axial and equatorial conformers are, therefore, expected to overlap in these peaks. As shown in Fig. 3(a), the e- $\mathrm{C}_{6} \mathrm{H}_{11} \mathrm{Br}\left(C_{S}, \mathrm{~A}^{\prime}\right) \rightarrow \mathrm{e}-$ $\mathrm{C}_{6} \mathrm{H}_{11} \mathrm{Br}^{+}\left(C_{\mathrm{S}}, \tilde{\mathbf{A}}^{+} \mathrm{A}^{\prime}\right)$ and $\mathrm{a}-\mathrm{C}_{6} \mathrm{H}_{11} \mathrm{Br}\left(C_{\mathrm{S}}, \mathrm{A}^{\prime}\right) \rightarrow \mathrm{a}-\mathrm{C}_{6} \mathrm{H}_{11} \mathrm{Br}^{+}\left(C_{\mathrm{S}}, \tilde{\mathbf{X}}^{+}\right.$ $\left.\mathrm{A}^{\prime}\right)$ bands have similar spectral contours, only with slightly different thresholds. Franck-Condon calculations predict no distinct vibrational progression for e- $\mathrm{C}_{6} \mathrm{H}_{11} \mathrm{Br}\left(C_{\mathrm{S}}, \mathrm{A}^{\prime}\right) \rightarrow$ e- $\mathrm{C}_{6} \mathrm{H}_{11} \mathrm{Br}^{+}\left(C_{1}, \tilde{\mathbf{X}}^{+}\right.$ pseudo- $\left.\mathrm{A}^{\prime \prime}\right)$, but only a broadband instead, which spans the $9.7 \mathrm{eV}-$ $10.3 \mathrm{eV}$ energy range. At first glance, the limited spectral complexity of the $\mathrm{X}=\mathrm{Br}$ TPES appears to be insufficient to argue for three contributing transitions. However, if, as predicted, the main peak, which gains a shoulder in $\mathrm{X}=\mathrm{I}$, is due to the origin transition, its large width strongly indicates a second contribution of a- $\mathrm{C}_{6} \mathrm{H}_{11} \mathrm{Br}$ $\left(C_{S}, \mathrm{~A}^{\prime}\right) \rightarrow$ a- $\mathrm{C}_{6} \mathrm{H}_{11} \mathrm{Br}^{+}\left(C_{S}, \tilde{\mathbf{X}}^{+} \mathrm{A}^{\prime}\right)$. For the e- $\mathrm{C}_{6} \mathrm{H}_{11} \mathrm{Br}\left(C_{S}, \mathrm{~A}^{\prime}\right)$ $\rightarrow \mathrm{e}-\mathrm{C}_{6} \mathrm{H}_{11} \mathrm{Br}^{+}\left(C_{1}, \tilde{\mathbf{X}}^{+}\right.$pseudo- $\left.\mathrm{A}^{\prime \prime}\right)$ transition, its presence is revealed by the TPES tail extending to below $9.8 \mathrm{eV}$. Thus, by modeling the experimental TPES, the contributions of three ionization transitions are clearly identified. The band origins are determined as $9.70 \mathrm{eV}$ for e- $\mathrm{C}_{6} \mathrm{H}_{11} \mathrm{Br}\left(C_{S}, \mathrm{~A}^{\prime}\right) \rightarrow \mathrm{e}-\mathrm{C}_{6} \mathrm{H}_{11} \mathrm{Br}^{+}\left(C_{1}, \tilde{\mathbf{X}}^{+}\right.$pseudo- $\left.\mathrm{A}^{\prime \prime}\right)$, $9.84 \pm 0.01 \mathrm{eV}$ for e- $\mathrm{C}_{6} \mathrm{H}_{11} \mathrm{Br}\left(C_{S}, \mathrm{~A}^{\prime}\right) \rightarrow \mathrm{e}-\mathrm{C}_{6} \mathrm{H}_{11} \mathrm{Br}^{+}\left(C_{S}, \tilde{\mathrm{A}}^{+} \mathrm{A}^{\prime}\right)$, and $9.83 \mathrm{eV}$ for a- $\mathrm{C}_{6} \mathrm{H}_{11} \mathrm{Br}\left(C_{\mathrm{S}}, \mathrm{A}^{\prime}\right) \rightarrow \mathrm{a}-\mathrm{C}_{6} \mathrm{H}_{11} \mathrm{Br}^{+}\left(C_{\mathrm{S}}, \tilde{\mathbf{X}}^{+} \mathrm{A}^{\prime}\right)$. Considering the Stark shift, the adiabatic ionization energies are $9.71 \mathrm{eV}$ for e- $\mathrm{C}_{6} \mathrm{H}_{11} \mathrm{Br}^{+}\left(C_{1}, \tilde{\mathbf{X}}^{+}\right.$pseudo- $\left.\mathrm{A}^{\prime \prime}\right), 9.85 \pm 0.01$ for e- $\mathrm{C}_{6} \mathrm{H}_{11} \mathrm{Br}^{+}\left(C_{S}\right.$, $\left.\tilde{\mathbf{A}}^{+} \mathrm{A}^{\prime}\right)$, and $9.84 \mathrm{eV}$ for a- $\mathrm{C}_{6} \mathrm{H}_{11} \mathrm{Br}^{+}\left(C_{S}, \tilde{\mathbf{X}}^{+} \mathrm{A}^{\prime}\right)$, respectively. The latter two values are consistent with the vacuum ultraviolet massanalyzed threshold ionization (VUV-MATI) results, but FranckCondon calculations indicate that they were falsely assigned as the ionization energies to $\mathrm{e}-\mathrm{C}_{6} \mathrm{H}_{11} \mathrm{Br}^{+}\left(C_{1}\right)$ and a- $\mathrm{C}_{6} \mathrm{H}_{11} \mathrm{Br}^{+}\left(C_{5}\right){ }^{50}$ The true adiabatic ionization energy of e- $\mathrm{C}_{6} \mathrm{H}_{11} \mathrm{Br}$ to the $\tilde{\mathbf{X}}^{+}$pseudo${ }^{2} \mathrm{~A}^{\prime \prime}$ state of $C_{1}$ symmetry lies below, and the VUV-MATI spectrum identified the transition to the $\tilde{\mathbf{A}}^{+}{ }^{2} \mathrm{~A}^{\prime}$ state of $C_{S}$ symmetry, which involves less geometry relaxation and exhibits a strong $0-0$ transition.

When the sum of the Franck-Condon spectral traces for the $9.8 \mathrm{eV}-10.0 \mathrm{eV}$ band is shifted by $0.30 \mathrm{eV}$, it reproduces the higherlying spin-orbit state with the dominant peak at $10.14 \mathrm{eV}$. As the overall signal is dominated by the equatorial $\tilde{\mathbf{A}}^{+2} \mathrm{~A}^{\prime}$ state, this shift is most sensitive to its SOC constant. As mentioned previously, this splitting agrees with the one observed in bromomethane and is about two thirds of the spin-orbit splitting between the ${ }^{2} \mathrm{P}_{3 / 2}$ and ${ }^{2} \mathrm{P}_{1 / 2}$ states of the bromine atom.

Similarly, the first TPES band of $\mathrm{C}_{6} \mathrm{H}_{11} \mathrm{I}$ is successfully modeled assuming analogous contributions in the Franck-Condon simulation, as shown in Fig. 3(b). The strongest vibrational peak is assigned as the 0-0 transition of e- $\mathrm{C}_{6} \mathrm{H}_{11} \mathrm{I}\left(C_{S}, \mathrm{~A}^{\prime}\right) \rightarrow \mathrm{e}-\mathrm{C}_{6} \mathrm{H}_{11} \mathrm{I}^{+}\left(C_{S}, \tilde{\mathrm{A}}^{+} \mathrm{A}^{\prime}\right)$, at a peak position of $9.00 \pm 0.01 \mathrm{eV}$. The shoulder at lower energy is due to the combined contribution of the a- $\mathrm{C}_{6} \mathrm{H}_{11} \mathrm{I}\left(C_{S}, \mathrm{~A}^{\prime}\right) \rightarrow$ a- $\mathrm{C}_{6} \mathrm{H}_{11} \mathrm{I}^{+}\left(C_{S}, \tilde{\mathbf{X}}^{+} \mathrm{A}^{\prime}\right)$ and e- $\mathrm{C}_{6} \mathrm{H}_{11} \mathrm{I}\left(C_{S}, \mathrm{~A}^{\prime}\right) \rightarrow \mathrm{e}-\mathrm{C}_{6} \mathrm{H}_{11} \mathrm{I}^{+}\left(C_{1}\right.$, $\tilde{\mathbf{X}}^{+}$pseudo- $\left.\mathrm{A}^{\prime \prime}\right)$ transitions, and the corresponding origins are suggested at $8.97 \mathrm{eV}$ and $8.98 \mathrm{eV}$, respectively. Considering the Stark shift, the adiabatic ionization energies to these final ionic states are $9.01 \pm 0.01 \mathrm{eV}, 8.98 \mathrm{eV}$, and $8.99 \mathrm{eV}$, respectively, meaning that the three electronic states are indeed very close in energy, and only their spectral fingerprint differs greatly due to the different geometry change upon ionization (see below). Spin-orbit coupling is also clearly observed in the TPES of Fig. 3(b). However, the $0.49 \mathrm{eV}$ splitting, analogously determined for $\mathrm{X}=\mathrm{Br}$ and dominated by SOC in the equatorial $\tilde{A}^{+2} \mathrm{~A}^{\prime}$ state, is only half of the spin-orbit coupling in the iodine atom and significantly smaller than what was observed in iodomethane. ${ }^{64,70}$ Additionally, the broadened and washed-out vibrational structure in the ${ }^{2} \mathrm{P}_{1 / 2}$ spin-orbit band implies a short lifetime of the spin-orbit excited state.

\section{Dyson molecular orbital analysis}

EOM-IP-CCSD Dyson orbital analysis confirmed that, regardless of the halogen substituent, vertical ionization of the equatorial conformers e- $\mathrm{C}_{6} \mathrm{H}_{11} \mathrm{X}$ and the axial conformer a- $\mathrm{C}_{6} \mathrm{H}_{11} \mathrm{~F}$ takes place by creating an electron hole of $a^{\prime \prime}$ and $a^{\prime}$ symmetry to the $\tilde{\mathbf{X}}^{+}$and $\tilde{\mathbf{A}}^{+}$ states, respectively (Fig. 4). Vertical ionization energies are swapped for a- $\mathrm{C}_{6} \mathrm{H}_{11} \mathrm{X}(\mathrm{X}=\mathrm{Cl}, \mathrm{Br}$, and $\mathrm{I})$, which show a more stable $\mathrm{A}^{\prime}$ state than the $\mathrm{A}^{\prime \prime}$ state at the neutral geometry. However, since geometry relaxation is more pronounced in the $\mathrm{A}^{\prime \prime}$ state, this does not necessarily mean that the $\tilde{\mathbf{X}}^{+}$and $\tilde{\mathbf{A}}^{+}$state symmetries are swapped (see Table I for more details). Moreover, the halogen lone-pair character of the Dyson orbitals increases with an increase in the halogen size, meaning that the charge is more and more located on the halogen, as it plays a more prominent role in ionization as opposed to the cyclohexane ring.

In the unsubstituted cyclohexane, $\mathrm{C}_{6} \mathrm{H}_{12}$, the $\mathrm{HOMO}$ is a doubly degenerate $e_{\mathrm{g}}$ orbital within the $S_{6}$ point group. These two orbitals mostly resemble the $a^{\prime}$ and $a^{\prime \prime}$ Dyson orbitals shown for axial fluorocyclohexane. The degeneracy is lifted upon halogen substitution, and the resulting splitting is much larger in the equatorial conformer than in the axial one, with the totally symmetric $\mathrm{A}^{\prime}$ state destabilized (see $\mathrm{X}=\mathrm{F}$ in Fig. 5). As the halogen size increases, the Dyson orbitals shown in Fig. 4 and the HOMO and HOMO - 1 molecular orbitals become dominated by the halogen lone pair.

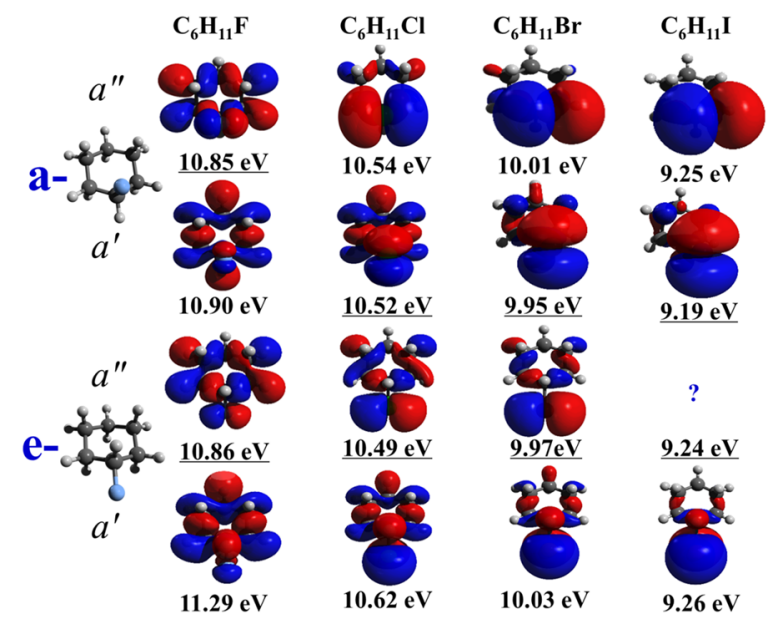

FIG. 4. Dyson orbitals in axial (a-) and equatorial (e-) halocyclohexane $\mathrm{C}_{6} \mathrm{H}_{11} \mathrm{X}$ corresponding to vertical ionization to the lowest $A^{\prime}$ and $A^{\prime \prime}$ states. The vertical ionization energies are shown with the lower one underlined. Because of a bug in the cube file calculation, we could not plot the $a^{\prime \prime}$ Dyson orbital for equatorial $\mathrm{C}_{6} \mathrm{H}_{11} \mathrm{l}$. 


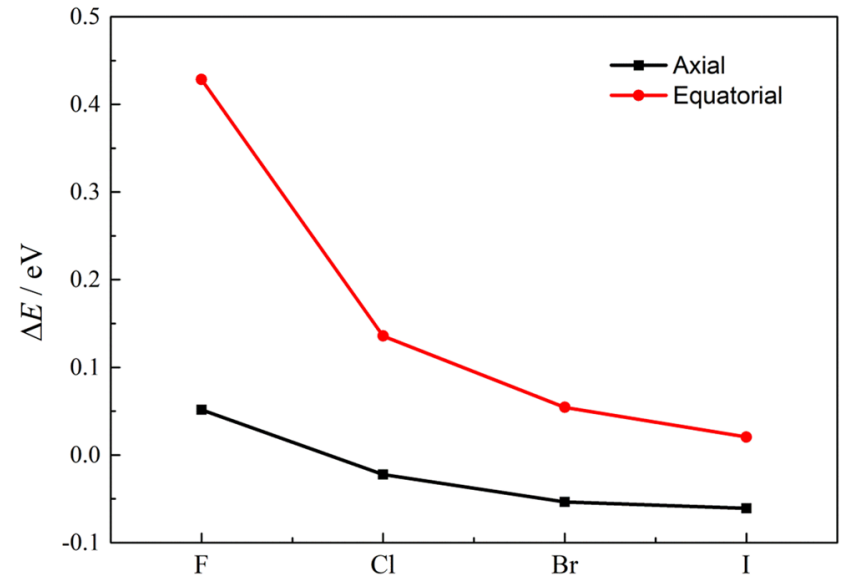

FIG. 5. Difference between the vertical ionization energy of the ${ }^{2} A^{\prime}$ and ${ }^{2} A^{\prime \prime}$ states of $\mathrm{C}_{6} \mathrm{H}_{11} \mathrm{X}$ in the axial and equatorial conformers.

Thus, the splitting between them is determined by the perturbation of the differently oriented halogen lone pair hole with respect to the cyclohexane ring. This slightly different type of perturbative coupling stabilizes the $\mathrm{A}^{\prime}$ cation state more than the $\mathrm{A}^{\prime \prime}$ state, and the vertical transition to the $A^{\prime}$ state energy is lower than that to the $\mathrm{A}^{\prime \prime}$ state in the axial conformer of $\mathrm{X}=\mathrm{Cl}$. However, because of the larger geometry relaxation of the $\mathrm{A}^{\prime \prime}$ state (see below), the ground state cation is still the $\tilde{\mathbf{X}}^{+}$pseudo- ${ }^{2} \mathrm{~A}^{\prime \prime}$ state of $C_{1}$ symmetry in axial $\mathrm{X}=\mathrm{Cl}$ and only switches to the $\tilde{\mathbf{X}}^{+2} \mathrm{~A}^{\prime}$ state in axial $\mathrm{X}=\mathrm{Br}$.

\section{Geometry relaxation upon ionization}

We optimized the geometries of axial and equatorial $\mathrm{C}_{6} \mathrm{H}_{11} \mathrm{X}^{+}$ $\left(\mathrm{X}=\mathrm{Cl}, \mathrm{Br}\right.$, and I) cations in the two lowest-lying $\tilde{\mathbf{X}}^{+}$and $\tilde{\mathbf{A}}^{+}$electronic states while conserving $C_{S}$ symmetry and also by allowing the geometry to relax to $C_{1}$. For completeness, we will also discuss $\mathrm{X}=\mathrm{F}$ here, for which the experimental data analysis has been reported before. ${ }^{27}$ Compared with the neutral geometry, the geometry change upon ionization is similar in $\mathrm{C}_{6} \mathrm{H}_{11} \mathrm{~F}$ and $\mathrm{C}_{6} \mathrm{H}_{11} \mathrm{Cl}$ and mainly concerns the ring geometry. The $\mathrm{C} 2-\mathrm{C} 3$ and $\mathrm{C} 5-\mathrm{C} 6$ bond lengths increase significantly in the $\tilde{\mathrm{A}}^{+}{ }^{2} \mathrm{~A}^{\prime}$ state, while the $\mathrm{C} 1-\mathrm{C} 2$ and C1-C6 bond lengths increase significantly in the $\tilde{\mathbf{X}}^{+2} \mathrm{~A}^{\prime \prime}$ state of the cation (Fig. 6). When the symmetry is relaxed in the $\tilde{\mathbf{X}}^{+}$pseudo${ }^{2} \mathrm{~A}^{\prime \prime}$ state, only the $\mathrm{C} 1-\mathrm{C} 2$ bond length increases markedly. In the $\mathrm{C}_{6} \mathrm{H}_{11} \mathrm{Br}^{+}$and $\mathrm{C}_{6} \mathrm{H}_{11} \mathrm{I}^{+}$cations ${ }^{2} \mathrm{~A}^{\prime}$ and ${ }^{2} \mathrm{~A}^{\prime \prime}$ states, the main geometry change upon ionization is the increase in the $\mathrm{C}-\mathrm{X}$ bond length compared to the neutral structure. Furthermore, the relaxation into the pseudo- $\mathrm{A}^{\prime \prime}$ state is associated with the halogen moving out of the original symmetry plane of the molecule instead of $\mathrm{C} 1-\mathrm{C} 2$ bond elongation. Some representative bond lengths are summarized for the optimized $\mathrm{C}_{6} \mathrm{H}_{11} \mathrm{~F}$ and $\mathrm{C}_{6} \mathrm{H}_{11} \mathrm{Br}$ neutrals and cations in Fig. 6.

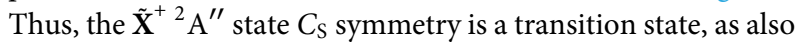
confirmed by the frequency analysis, and it relaxes to an asymmetric $C_{1}$ structure when the symmetry is broken. Furthermore, in the axial conformer of $\mathrm{X}=\mathrm{Br}$ and $\mathrm{I}$, the (pseudo- $)^{2} \mathrm{~A}^{\prime \prime}$ state becomes an
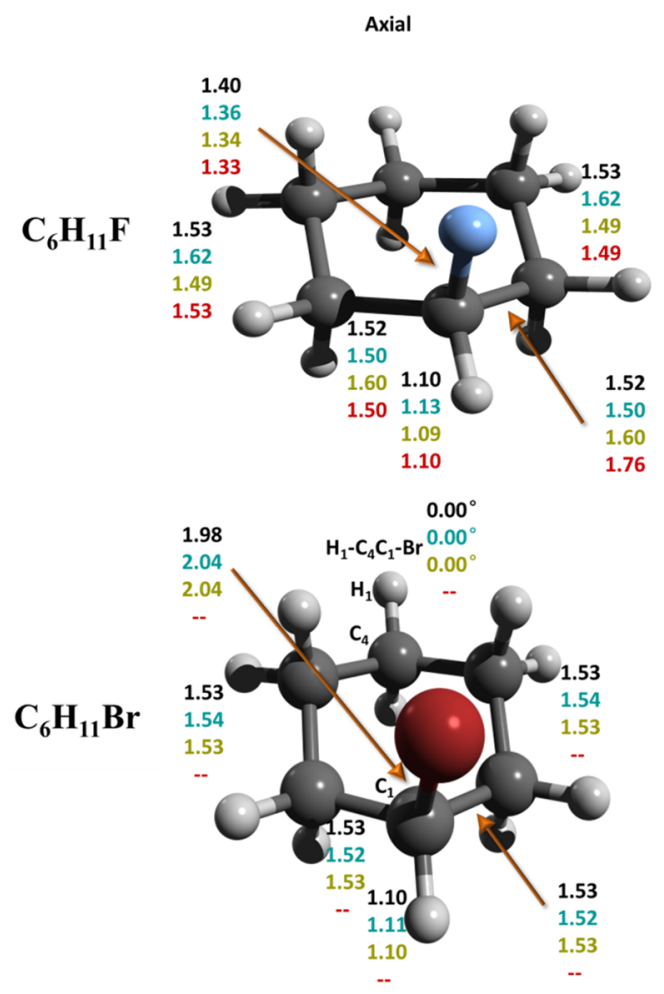

Equatorial
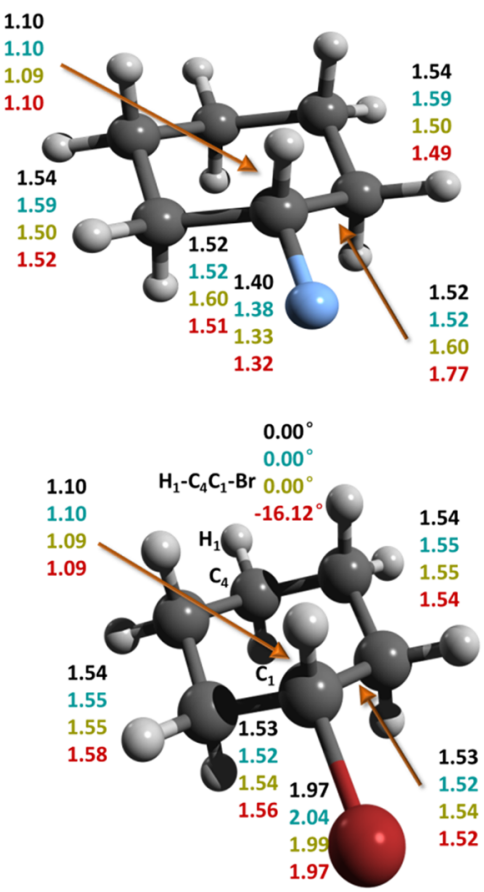

FIG. 6. Representative bond lengths in $\AA$ in $a-C_{6} \mathrm{H}_{11} \mathrm{~F}^{(+)}$, e- $\mathrm{C}_{6} \mathrm{H}_{11} \mathrm{~F}^{(+)}$, a$\mathrm{C}_{6} \mathrm{H}_{11} \mathrm{Br}^{(+)}$, and $\mathrm{e}-\mathrm{C}_{6} \mathrm{H}_{11} \mathrm{Br}^{(+)}$in $\mathrm{C}_{S}$ and $\mathrm{C}_{1}$ symmetries. $\mathrm{A} \mathrm{Br}$ torsional angle is also shown to illustrate its wagging out of the symmetry plane of the molecule in pseudo- $\mathrm{A}^{\prime \prime} \mathrm{e}-\mathrm{C}_{6} \mathrm{H}_{11} \mathrm{Br}^{+}$. Values from top to bottom correspond to the neutral ground state, the $\tilde{\mathbf{A}}^{+}{ }^{2} \mathrm{~A}^{\prime}$ state, the $\tilde{\mathbf{X}}^{+}$ ${ }^{2} \mathrm{~A}^{\prime \prime}$ state, and the relaxed $\tilde{\mathbf{X}}^{+}$pseudo${ }^{2} A^{\prime \prime}$ state in $C_{1}$ symmetry, respectively. 
excited state, and the ground state is the totally symmetric $\tilde{\mathbf{X}}^{+2} \mathrm{~A}^{\prime}$ state.

Although the symmetry of the ground state changes as a function of halogen substituent as well as the conformation, ground-state
DFT calculations could be used in the Franck-Condon simulation of the spectra, thanks to the large geometry difference between the $\mathrm{A}^{\prime}$ and (pseudo-) $\mathrm{A}^{\prime \prime}$ states, which also means that, at their respective optimized geometry, the corresponding electronic state is often

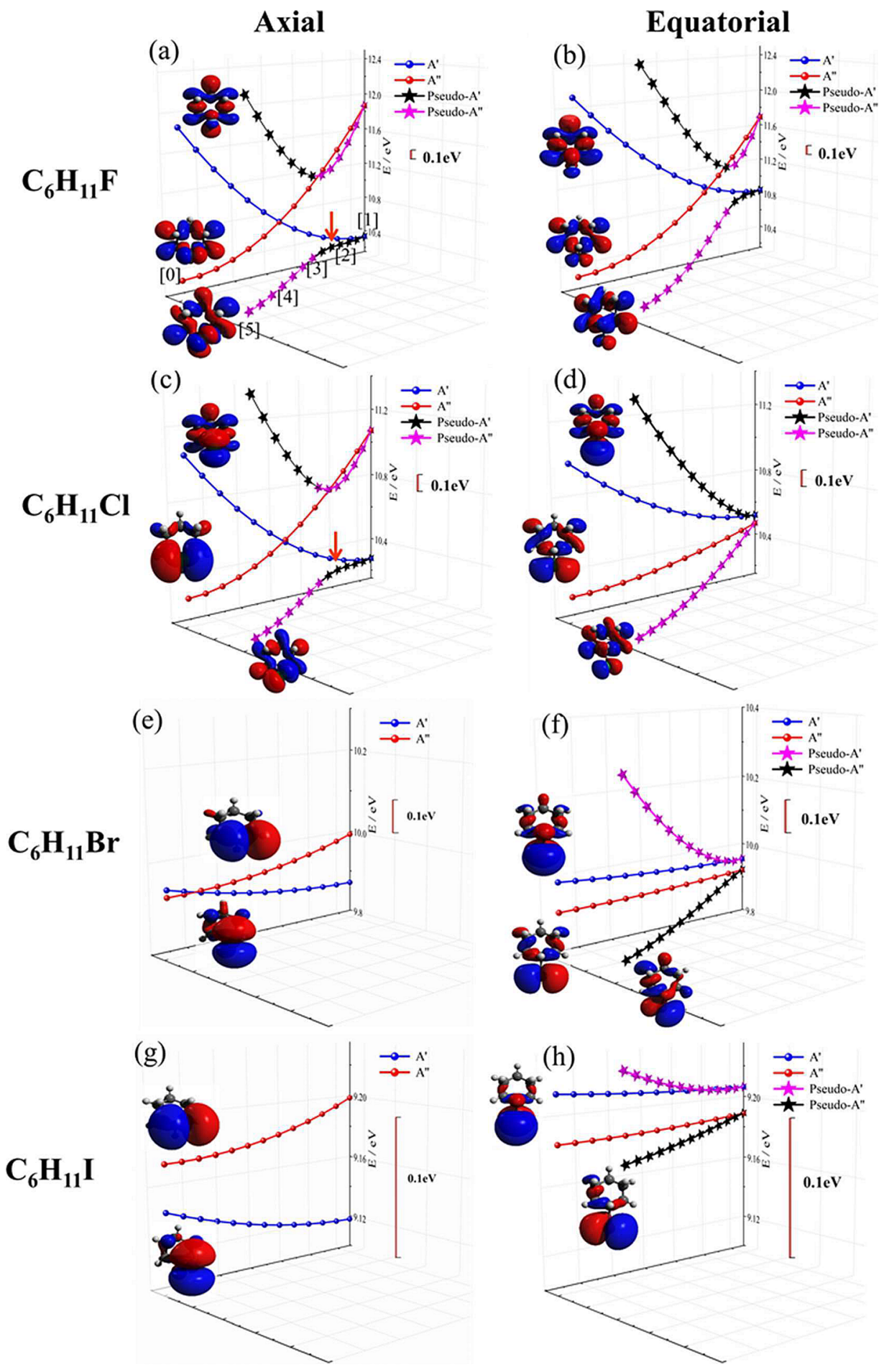

FIG. 7. Potential energy curves along pathways connecting the lowest two electronic states from the $A^{\prime}$ minimum to the $A^{\prime \prime}$ transition state in $C_{S}$ symmetry (dots) and from the $A^{\prime}$ minimum to the pseudo-A" minimum without symmetry (stars) for the axial [(a), (c), (e), and (g)] and equatorial $[(b),(d),(f)$, and $(h)]$ isomers of $X=F[(a)$ and $(b)], C l[(c)$ and (d)], $\mathrm{Br}[(\mathrm{e})$ and $(\mathrm{f})]$, and I [(g) and (h)]. The barrier along the $C_{1}$ path is marked by an orange arrow in the axial conformer of $\mathrm{X}=\mathrm{F}$ and $\mathrm{Cl}$. Representative Dyson orbitals are also shown. 
lowest in energy, and the excitation energy to the next state is, especially for $\mathrm{X}=\mathrm{F}$ and $\mathrm{Cl}$, quite large. The $\mathrm{A}^{\prime}$ state could also be addressed by ground state DFT calculations by judicious choice of functional for the equatorial conformers of $\mathrm{X}=\mathrm{Br}$ and $\mathrm{I}$, in which EOM-IP-CCSD calculations predict the $\mathrm{A}^{\prime}$ and $\mathrm{A}^{\prime \prime}$ states to be nearly degenerate, especially in $C_{S}$ symmetry.

\section{E. Coupling between the $A^{\prime}$ and $A^{\prime \prime}$ states: $A$ conical intersection in $C_{5}$, avoided crossing in $C_{1}$}

Because of the diminishing energy differences between the $\mathrm{A}^{\prime}$ and $\mathrm{A}^{\prime \prime}$ states as a function of halogen size and the more pronounced halogen lone-pair character of the Dyson orbitals for $\mathrm{X}=\mathrm{Br}$ and I, fluoro- and chlorocyclohexane cations can be thought of more as a perturbed cyclohexane, whereas bromo- and iodocyclohexane cations exhibit a halogen lone pair electron hole perturbed by the carbon ring. Focusing on the former picture, the non-degenerate $\mathrm{A}^{\prime}$ and $\mathrm{A}^{\prime \prime}$ states arise from a degenerate pair of $e_{\mathrm{g}}$ molecular orbitals in cyclohexane by symmetry breaking due to the halogen substituent and the interaction of the ring with the halogen lone pair, which is reminiscent of Jahn-Teller coupling in the cyclohexane cation. In $C_{S}$ symmetry, the $p$-type halogen lone pair electron hole in the cation may either be symmetric or antisymmetric, i.e., aligned perpendicular to or parallel with the $\mathrm{C}_{6}$ ring. This is also clearly seen in the Dyson orbitals in Fig. 4 for vertical ionization at the neutral geometry in $C_{S}$ symmetry. However, this insight also offers a path to connect these two states, namely, by interconverting $a^{\prime}$ and $a^{\prime \prime}$ by rotating the halogen lone pair along the $\mathrm{C}-\mathrm{X}$ axis, which entails a concurrent generalized rotation of the orbital on the carbon ring, as well. This is only possible by breaking the symmetry, and the corresponding nuclear geometries will also lose the mirror plane. Thus, in a generic sense, each conformer cation (equatorial and axial) has two electronic conformations depending on the orientation of the electron hole.

Three stationary points are defined to help understand the potential energy surface and the coupling between the $\mathrm{A}^{\prime}$ and $\mathrm{A}^{\prime \prime}$ states. First, ionization from the $a^{\prime}$ Dyson orbital results in an $\mathrm{A}^{\prime}$ state, which optimizes to a $C_{\mathrm{S}}$ minimum, which is the most stable structure in the axial conformer of $\mathrm{X}=\mathrm{Br}$ and $\mathrm{I}$. Ionization from the $a^{\prime \prime}$ Dyson orbital yields an $\mathrm{A}^{\prime \prime}$ state, which can be optimized to a transition state in $C_{S}$, and relaxes by symmetry breaking to the pseudo- $\mathrm{A}^{\prime \prime}$ global minimum in the axial conformer of $\mathrm{X}=\mathrm{F}$ and $\mathrm{Cl}$ and in the equatorial conformer of $\mathrm{X}=\mathrm{F}, \mathrm{Cl}, \mathrm{Br}$, and $\mathrm{I}$. Because of the near-degeneracy of electronic states, the $C_{1}$ pseudo- $\mathrm{A}^{\prime \prime}$ minima could not be located in the axial conformer of $\mathrm{X}=\mathrm{Br}$ and $\mathrm{I}$.

Two paths were then defined, connecting the $\mathrm{A}^{\prime}$ minimum and the $\mathrm{A}^{\prime \prime}$ transition states in $C_{\mathrm{S}}$ symmetry and the $\mathrm{A}^{\prime}$ and the pseudo$\mathrm{A}^{\prime \prime}$ minima in $C_{1}$ symmetry by interpolation in internal redundant coordinates. The paths, shown in Fig. 7 for the equatorial and axial isomers, include the $C_{\mathrm{S}}$ path in the left pane and the $C_{1}$ path at a slight angle to it. What is visible in plots Figs. $7(\mathrm{a})-7(\mathrm{c})$ is a classic example of a diabolical conical intersection in $C_{\mathrm{S}}$ symmetry, turning into an avoided crossing after symmetry breaking. The rotation of the lowest-energy Dyson orbital in fluorocyclohexane along the path shown in Fig. 7(a) is also readily seen in Fig. 8. Ground and excited state potential energy curves are clearly distinct in $C_{1}$ symmetry, although structure [1] is of $\mathrm{A}^{\prime}$ symmetry and [5], i.e., the pseudo- $A^{\prime \prime}$ minimum, is barely separated from $[\mathbf{0}]$ of $A^{\prime \prime}$ symmetry.

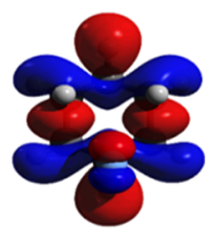

[1]

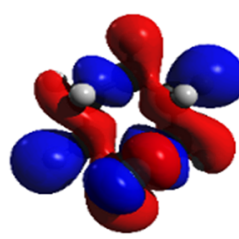

[4]

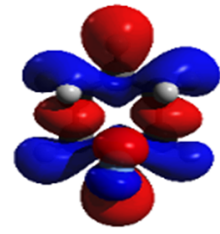

[2]

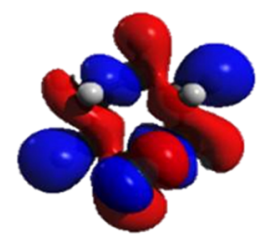

[5]

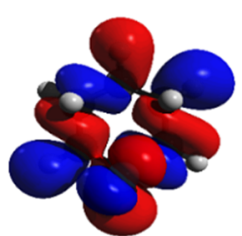

[3]

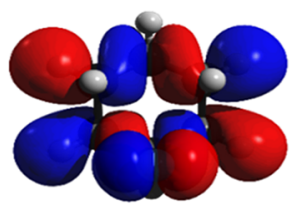

[0]
FIG. 8. Dyson orbital rotation for ionization into the lowest energy pseudo- $\mathrm{A}^{\prime} / \mathrm{A}^{\prime \prime}$ state in axial fluorocyclohexane. The structures [1-5] refer to the path shown in Fig. 7 (a) with [0] corresponding to the $A^{\prime \prime}$ state and [1] to the $A^{\prime}$ state.

As shown above, the spectral contributions and vibrational fingerprints of the two states are also clearly distinguishable when there is a barrier between the two.

\section{CONCLUSIONS}

The threshold photoelectron spectra of $\mathrm{C}_{6} \mathrm{H}_{11} \mathrm{X}(\mathrm{X}=\mathrm{Cl}, \mathrm{Br}$, and I) are reported and analyzed with the help of DFT FranckCondon factor simulations, EOM-IP-CCSD ionization energy, and Dyson orbital calculations. The role of the axial and equatorial conformational isomerism is also discussed in the context of our recent analysis of the $\mathrm{C}_{6} \mathrm{H}_{11} \mathrm{~F}$ TPES. The geometry relaxation upon ionization depends on the halogen size and the symmetry of the electron hole. In $\mathrm{X}=\mathrm{F}$ and $\mathrm{Cl}$, the removal of an $a^{\prime}$ electron, which corresponds to a halogen lone pair along the symmetry plane, leads to an elongation of the $\mathrm{C} 2-\mathrm{C} 3$ and $\mathrm{C} 5-\mathrm{C} 6$ bond lengths. In most halogens and conformers, the ion state formed by the removal of an $a^{\prime \prime}$ electron, i.e., the halogen lone pair perpendicular to the symmetry plane, is more stable and can further relax by an elongation of the $\mathrm{C} 1-\mathrm{C} 2$ bond $(\mathrm{X}=\mathrm{F}$ and $\mathrm{Cl})$ or by wagging the halogen substituent out of the symmetry plane $(\mathrm{X}=\mathrm{Br}$ and $\mathrm{I})$. This difference in behavior is due to the HOMO being a ring orbital perturbed by the halogen lone pair in $\mathrm{X}=\mathrm{F}$ and $\mathrm{Cl}$, as opposed to a halogen lone pair perturbed by the carbon ring in $\mathrm{X}=\mathrm{Br}$ and $\mathrm{I}$. While the $\mathrm{A}^{\prime}$ and $\mathrm{A}^{\prime \prime}$ states, distinguished by the orientation of the electron hole, are distinct in $C_{S}$ symmetry, which also contain the seam of the conical intersection between them, they are smoothly and often barrierlessly connected in $C_{1}$ symmetry. However, when there is an avoided crossing and a barrier between them, we could identify the spectral contribution of both states to the TPES.

Density functional theory Franck-Condon simulations were guided by insights from the EOM-IP-CCSD results. For $\mathrm{C}_{6} \mathrm{H}_{11} \mathrm{Cl}$, three ionization transitions could be identified, analogously to $\mathrm{C}_{6} \mathrm{H}_{11} \mathrm{~F}:(i)$ e- $\mathrm{C}_{6} \mathrm{H}_{11} \mathrm{Cl}\left(C_{\mathrm{S}}, \mathrm{A}^{\prime}\right) \rightarrow \mathrm{e}-\mathrm{C}_{6} \mathrm{H}_{11} \mathrm{Cl}^{+}\left(C_{1}, \tilde{\mathbf{X}}^{+}\right.$pseudo- $\left.\mathrm{A}^{\prime \prime}\right)$, 
(ii) a- $\mathrm{C}_{6} \mathrm{H}_{11} \mathrm{Cl}\left(\mathrm{C}_{\mathrm{S}}, \mathrm{A}^{\prime}\right) \rightarrow$ a- $\mathrm{C}_{6} \mathrm{H}_{11} \mathrm{Cl}^{+}\left(\mathrm{C}_{1}, \tilde{\mathbf{X}}^{+}\right.$pseudo- $\left.\mathrm{A}^{\prime \prime}\right)$, and (iii) a- $\mathrm{C}_{6} \mathrm{H}_{11} \mathrm{Cl}\left(C_{S}, \mathrm{~A}^{\prime}\right) \rightarrow$ a- $\mathrm{C}_{6} \mathrm{H}_{11} \mathrm{Cl}^{+}\left(C_{S}, \tilde{\mathbf{A}}^{+} \mathrm{A}^{\prime}\right)$ at 10.06 $\pm 0.01,10.06$, and 10.11, respectively. Franck-Condon simulations of $\mathrm{C}_{6} \mathrm{H}_{11} \mathrm{Br}$ and $\mathrm{C}_{6} \mathrm{H}_{11} \mathrm{I}$ also identified three, albeit different transitions to contribute to the spectrum for both $\mathrm{X}=\mathrm{Br}$ and I: (iv) e- $\mathrm{C}_{6} \mathrm{H}_{11} \mathrm{Br}\left(C_{S}, \mathrm{~A}^{\prime}\right) \rightarrow \mathrm{e}-\mathrm{C}_{6} \mathrm{H}_{11} \mathrm{Br}^{+}\left(C_{1}, \tilde{\mathbf{X}}^{+}\right.$pseudo$\left.\mathrm{A}^{\prime \prime}\right),(v) \mathrm{a}-\mathrm{C}_{6} \mathrm{H}_{11} \mathrm{Br}\left(C_{S}, \mathrm{~A}^{\prime}\right) \rightarrow \mathrm{a}-\mathrm{C}_{6} \mathrm{H}_{11} \mathrm{Br}^{+}\left(C_{S}, \tilde{\mathbf{X}}^{+} \mathrm{A}^{\prime}\right)$, and $(v i)$ e- $C_{6} \mathrm{H}_{11} \mathrm{Br}\left(C_{S}, \mathrm{~A}^{\prime}\right) \rightarrow \mathrm{e}-\mathrm{C}_{6} \mathrm{H}_{11} \mathrm{Br}^{+}\left(C_{S}, \tilde{\mathbf{A}}^{+} \mathrm{A}^{\prime}\right)$ at 9.71, 9.84, and $9.85 \pm 0.01 \mathrm{eV}$, as well as (vii) a- $\mathrm{C}_{6} \mathrm{H}_{11} \mathrm{I}\left(C_{S}, \mathrm{~A}^{\prime}\right)$ $\rightarrow$ a- $\mathrm{C}_{6} \mathrm{H}_{11} \mathrm{I}^{+}\left(C_{\mathrm{S}}, \tilde{\mathbf{X}}^{+} \mathrm{A}^{\prime}\right)$, (viii) e- $\mathrm{C}_{6} \mathrm{H}_{11} \mathrm{I}\left(C_{\mathrm{S}}, \mathrm{A}^{\prime}\right) \rightarrow \mathrm{e}-\mathrm{C}_{6} \mathrm{H}_{11} \mathrm{I}^{+}\left(C_{1}\right.$, $\tilde{\mathbf{X}}^{+}$pseudo-A $\left.\mathrm{A}^{\prime \prime}\right)$, and $(i x) \mathrm{e}-\mathrm{C}_{6} \mathrm{H}_{11} \mathrm{I}\left(C_{S}, \mathrm{~A}^{\prime}\right) \rightarrow \mathrm{e}-\mathrm{C}_{6} \mathrm{H}_{11} \mathrm{I}^{+}\left(C_{S}, \tilde{\mathbf{A}}^{+} \mathrm{A}^{\prime}\right)$ at $8.98,8.99$, and $9.01 \pm 0.01 \mathrm{eV}$, respectively.

In light of these results, the origin transition was not seen in the ionization of $\mathrm{e}-\mathrm{C}_{6} \mathrm{H}_{11} \mathrm{Br}$ to the lowest-lying pseudo- $\mathrm{A}^{\prime \prime}$ state, and we revise the assignment of the previous VUV-MATI experiment. ${ }^{50}$ Although energy and spectral differences between the conformers decrease with an increase in the halogen size, the FranckCondon analysis also shows major differences between the ionization mechanisms and active transitions of axial and equatorial conformers.

\section{ACKNOWLEDGMENTS}

Experiments were carried out at the VUV beamline of the Swiss Light Source of the Paul Scherrer Institute. The financial support from the Swiss Federal Office of Energy (BFE Contract No. SI/501269-01) and the National Natural Science Foundation of China (Grant Nos. 21903079 and 21873089) is gratefully acknowledged. This work was also financially supported by the National Key Research and Development Program of China (Grant No. 2016YFF0200502) and the USTC-NSRL. X.W. appreciates the SSSTC scholarship (Grant No. EG-CN 01-042018) and thanks the China Scholarship Council (Grant No. 201806340001) for support.

\section{DATA AVAILABILITY}

The data that support the findings of this study are available from the corresponding author upon reasonable request.

\section{REFERENCES}

${ }^{1}$ S. T. Park, S. K. Kim, and M. S. Kim, Nature 415(6869), 306 (2002).

${ }^{2}$ M. H. Kim, L. Shen, H. Tao, T. J. Martinez, and A. G. Suits, Science 315(5818), 1561-1565 (2007).

${ }^{3}$ J. S. Lim, Y. S. Lee, and S. K. Kim, Angew. Chem., Int. Ed. 47(10), 1853-1856 (2008).

${ }^{4}$ K.-W. Choi, D.-S. Ahn, J.-H. Lee, and S. K. Kim, Chem. Commun. 16(10), 10411043 (2007).

${ }^{5}$ R. Chinchilla and C. Nájera, Chem. Rev. 114(3), 1783-1826 (2013).

${ }^{6}$ D. L. Osborn, P. Zou, H. Johnsen, C. C. Hayden, C. A. Taatjes, V. D. Knyazev, S. W. North, D. S. Peterka, M. Ahmed, and S. R. Leone, Rev. Sci. Instrum. 79(10), 104103 (2008)

${ }^{7}$ O. Kostko, B. Bandyopadhyay, and M. Ahmed, Annu. Rev. Phys. Chem. 67, 1940 (2016).

${ }^{8}$ S. Ullrich, G. Tarczay, X. Tong, C. E. Dessent, and K. Müller-Dethlefs, Angew. Chem., Int. Ed. 41(1), 166-168 (2002).

${ }^{9}$ J. McMurry, Organic Chemistry (Thomson-Brooks/Cole, Belmont, 2004).
${ }^{10}$ X. Tang, X. Zhou, M. Niu, S. Liu, J. Sun, X. Shan, F. Liu, and L. Sheng, Rev. Sci. Instrum. 80(11), 113101 (2009).

${ }^{11}$ A. Bodi, P. Hemberger, T. Gerber, and B. Sztáray, Rev. Sci. Instrum. 83(8), 083105 (2012).

${ }^{12}$ G. A. Garcia, B. K. Cunha de Miranda, M. Tia, S. Daly, and L. Nahon, Rev. Sci. Instrum. 84(5), 053112 (2013).

${ }^{13}$ T. Baer and R. P. Tuckett, Phys. Chem. Chem. Phys. 19(15), 9698-9723 (2017).

${ }^{14}$ X. Wu, X. Tang, X. Zhou, and S. Liu, Chin. J. Chem. Phys. 32(1), 11-22 (2019).

${ }^{15}$ A. Bodi, P. Hemberger, D. L. Osborn, and B. L. Sztáray, J. Phys. Chem. Lett. 4(17), 2948-2952 (2013).

${ }^{16}$ P. Hemberger and A. Bodi, CHIMIA Int. J. Chem. 72(4), 227-232 (2018).

${ }^{17}$ P. Hemberger, V. B. F. Custodis, A. Bodi, T. Gerber, and J. A. van Bokhoven, Nat. Commun. 8, 15946 (2017).

${ }^{18}$ X. Wu, G. Tang, H. Zhang, X. Zhou, S. Liu, F. Liu, L. Sheng, and B. Yan, Phys, Chem. Chem. Phys. 20(7), 4917-4925 (2018).

${ }^{19}$ X. Wu, T. Yu, Y. Chen, X. Zhou, S. Liu, X. Dai, F. Liu, and L. Sheng, Phys. Chem. Chem. Phys. 21(9), 4998-5005 (2019).

${ }^{20}$ M. F. Heringa, J. G. Slowik, A. S. Prévôt, U. Baltensperger, P. Hemberger, and A. Bodi, J. Phys. Chem. A 120(20), 3397-3405 (2016).

${ }^{21}$ K. Majer, R. Signorell, M. F. Heringa, M. Goldmann, P. Hemberger, and A. Bodi, Chem. - Eur. J. 25, 14192-14204 (2019).

${ }^{22}$ M. Steglich, V. B. Custodis, A. J. Trevitt, G. daSilva, A. Bodi, and P. Hemberger, J. Am. Chem. Soc. 139(41), 14348-14351 (2017).

${ }^{23}$ K. Voronova, K. M. Ervin, K. G. Torma, P. Hemberger, A. Bodi, T. Gerber, D. L. Osborn, and B. L. Sztáray, J. Phys. Chem. Lett. 9(3), 534-539 (2018).

${ }^{24}$ X. Wu, X. Zhou, P. Hemberger, and A. Bodi, Phys. Chem. Chem. Phys. 21(40), 22238-22247 (2019).

${ }^{25}$ M. Lang, F. Holzmeier, P. Hemberger, and I. Fischer, J. Phys. Chem. A 119(17), 3995-4000 (2015).

${ }^{26}$ D. Krüger, P. Oßwald, M. Köhler, P. Hemberger, T. Bierkandt, Y. Karakaya, and T. Kasper, Combust. Flame 191, 343-352 (2018).

${ }^{27}$ X. Wu, X. Zhou, P. Hemberger, and A. Bodi, Phys. Chem. Chem. Phys. 22, 2351 (2020).

${ }^{28}$ A. Bodi and P. Hemberger, J. Phys. Chem. A 123(1), 272-283 (2019).

${ }^{29}$ A. Bodi, K. L. Sigurdardottir, Á. Kvaran, R. Bjornsson, and I. Arnason, J. Phys. Chem. A 120(46), 9188-9197 (2016).

${ }^{30}$ V. A. Atkinson, Acta Chem. Scand. 15(3), 599 (1961).

${ }^{31}$ Q. Shen and J. M. Peloquin, Acta Chem. Scand. 42a, 367 (1988).

${ }^{32}$ F. R. Jensen and C. H. Bushweller, J. Am. Chem. Soc. 91(12), 3223-3225 (1969).

${ }^{33}$ F. R. Jensen, C. H. Bushweller, and B. H. Beck, J. Am. Chem. Soc. 91(2), 344-351 (1969).

${ }^{34}$ D. Damiani and L. Ferretti, Chem. Phys. Lett. 21(3), 592-594 (1973).

${ }^{35}$ D. Damiani, F. Scappini, W. Caminati, and G. Corbelli, J. Mol. Spectrosc. 100(1), 36-53 (1983).

${ }^{36}$ W. Caminati, F. Scappini, and D. Damiani, J. Mol. Spectrosc. 108(2), 287-298 (1984).

${ }^{37}$ W. Caminati, D. Damiani, and F. Scappini, J. Mol. Spectrosc. 104(1), 183-193 (1984).

${ }^{38}$ S. Holly, G. Jalsovszky, and O. Egyed, J. Mol. Struct. 79, 465-468 (1982).

${ }^{39}$ C. Zheng, S. Subramaniam, V. F. Kalasinsky, and J. R. Durig, J. Mol. Struct. 785(1-3), 143-159 (2006).

${ }^{40}$ D. E. Bugay, C. H. Bushweller, C. T. Danehey, Jr., S. Hoogasian, J. A. Blersch, and W. R. Leenstra, J. Phys. Chem. 93(10), 3908-3911 (1989).

${ }^{41}$ M. Kolodziejski, G. Waliszewska, and H. Abramczyk, Chem. Phys. 213(1-3), 341-356 (1996).

${ }^{42}$ T. Woldbæk, Acta Chem. Scand. 36a, 641-656 (1982).

${ }^{43}$ J. R. Durig, A. M. El Defrawy, R. M. Ward, G. A. Guirgis, and T. K. Gounev, Struct. Chem. 19(4), 579 (2008).

${ }^{44}$ J. R. Durig, A. M. El Defrawy, R. M. Ward, G. A. Guirgis, and T. K. Gounev, J. Mol. Struct. 918(1-3), 26-38 (2009).

${ }^{45}$ E. Białkowska-Jaworska, M. Jaworski, and Z. Kisiel, J. Mol. Struct. 350(3), 247254 (1995). 
${ }^{46}$ C. A. Stortz, J. Phys. Org. Chem. 23(12), 1173-1186 (2010).

${ }^{47}$ Y. L. Sergeev, M. E. Akopyan, F. I. Vilesov, and Y. V. Chizhov, High Energy Chem. 7, 418-423 (1973).

${ }^{48}$ S. Tian, N. Kishimoto, and K. Ohno, J. Phys. Chem. A 106(28), 6541-6553 (2002).

${ }^{49}$ S. Tian, N. Kishimoto, and K. Ohno, J. Electron Spectrosc. Relat. Phenom. 125(3), 205-219 (2002).

${ }^{50}$ S. Han, H. S. Yoo, and S. K. Kim, J. Phys. Chem. A 114(37), 10005-10010 (2010).

${ }^{51}$ M. Johnson, A. Bodi, L. Schulz, and T. Gerber, Nucl. Instrum. Methods Phys. Res., Sect. A 610(2), 597-603 (2009).

${ }^{52}$ B. Sztáray, K. Voronova, K. G. Torma, K. J. Covert, A. Bodi, P. Hemberger, T. Gerber, and D. L. Osborn, J. Chem. Phys. 147(1), 013944 (2017).

${ }^{53}$ B. Sztáray and T. Baer, Rev. Sci. Instrum. 74(8), 3763-3768 (2003).

${ }^{54}$ A. Bodi, B. Sztáray, T. Baer, M. Johnson, and T. Gerber, Rev. Sci. Instrum. 78(8), 084102 (2007).

${ }^{55}$ F. Santoro, A. Lami, R. Improta, J. Bloino, and V. Barone, J. Chem. Phys, 128(22), 224311 (2008).

${ }^{56}$ M. J. Frisch, G. W. Trucks, H. B. Schlegel, G. E. Scuseria, M. A. Robb, J. R. Cheeseman, G. Scalmani, V. Barone, B. Mennucci, G. A. Petersson et al., Gaussian 16 Revision A.03, Gaussian, Inc., Wallingford, CT, 2016.

${ }^{57}$ Y. Shao, L. F. Molnar, Y. Jung, J. Kussmann, C. Ochsenfeld, S. T. Brown, A. T. Gilbert, L. V. Slipchenko, S. V. Levchenko, and D. P. O’Neill, Phys. Chem. Chem. Phys. 8(27), 3172-3191 (2006).

${ }^{58}$ C. Melania Oana and A. I. Krylov, J. Chem. Phys. 127(23), 234106 (2007).
${ }^{59}$ K. A. Peterson, D. Figgen, E. Goll, H. Stoll, and M. Dolg, J. Chem. Phys. 119, 11113 (2003).

${ }^{60}$ C. Peng, P. Y. Ayala, H. B. Schlegel, and M. J. Frisch, J. Comput. Chem. 17(1), 49-56 (1996).

${ }^{61}$ C. Botond, N. Balázs, C. József, and K. Mihály, J. Phys. Chem. A 117(26), 55185528 (2013).

${ }^{62}$ A. Kramida, Y. Ralchenko, J. Reader, and NIST ASD Team, NIST Atomic Spectra Database (version 5.7.1), National Institute of Standards and Technology, Gaithersburg, MD, available at https://physics.nist.gov/asd, 17 May 2020.

${ }^{63} \mathrm{~J}$. A. Hashmall and E. Heilbronner, Angew. Chem., Int. Ed. 9(4), 305-306 (1970).

${ }^{64}$ K. Kimura, S. Katsumata, Y. Achiba, H. Matsumoto, and S. Nagakura, Bull. Chem. Soc. Jpn. 46(2), 373-380 (1973).

${ }^{65}$ F. T. Chau and L. Karlsson, Phys. Scr. 16(5-6), 258 (1977).

${ }^{66}$ A. Bodi, N. S. Shuman, and T. Baer, Phys. Chem. Chem. Phys. 11(46), 1101311021 (2009)

${ }^{67}$ A. Candian, J. Bouwman, P. Hemberger, A. Bodi, and A. G. G. M. Tielens, Phys. Chem. Chem. Phys. 20, 5399-5406 (2018).

${ }^{68}$ J. L. Tech, J. Res. Natl. Bur. Stand., Sect. A 67A, 505-554 (1963).

${ }^{69}$ P. B. Davies, B. A. Thrush, A. J. Stone, and F. D. Wayne, Chem. Phys. Lett. 17(1), 19-21 (1972).

${ }^{70}$ E. Luc-Koenig, C. Morillon, and J. Vergès, Phys. Scr. 12(4), 199 (1975).

${ }^{71}$ S. Lunell, M. B. Huang, O. Claesson, and A. Lund, J. Chem. Phys. 82(11), 5121 (1985).

${ }^{72}$ D. R. Yarkony, Rev. Mod. Phys. 68(4), 985-1013 (1996). 